Original Research Paper

\title{
Green Environments and their Effect Upon Hospital Users
}

\author{
${ }^{1}$ Carol A. Haigh, ${ }^{2}$ Gary Witham, ${ }^{3}$ Jessica Thompson and ${ }^{4}$ Hilary Wood \\ ${ }^{1,2}$ Manchester Metropolitan University, UK M13 OJA, Manchester, United Kingdom \\ ${ }^{3,4}$ Red Rose Forest, Salford, UK M50 2GL, United Kingdom
}

\author{
Article history \\ Received: 12-02-2014 \\ Revised: 17-02-2014 \\ Accepted: 09-12-2014 \\ Corresponding Author: \\ Carol A. Haigh, \\ Manchester Metropolitan \\ University, UK M13 0JA, \\ Manchester, United Kingdom \\ Email: c.haigh@mmu.ac.uk
}

\begin{abstract}
Whilst there is significant academic and health care opinion is that green space both in and outside of institutions is both beneficial and desirable for hospital patients and workers, there is little in the literature to suggest that patients and staff recognise or identify 'good' and 'bad' natural environments. This study reports an exploration of the green environment around a large cancer treatment centre in the United Kingdom to evaluate the external hospital environment and the perceptions of various users of the hospital sites. The aim of this study was to investigate whether the individuals who used the hospital and local residents could identify the advantages of a green infrastructure and could comment upon the existing green examples and also suggest areas, which would benefit from a greener environment. National surveys in several countries have highlighted the common association with stress reduction and exposure to the natural environment. Access to garden areas was an important self-nurturing strategy for patients and staff. Self-nurturing was seen as crucial in allowing healthcare professionals as providing a method of dealing with the stress of care delivery. This was a mixed methods design, primarily quantitative but with a qualitative component. Quantitative data was gathered via a questionnaire whilst the qualitative elements came from a workshop. All data was collected in 2010. The respondents identified the hospital entrances, as being most on need of green planting; the workshop participants identified these as 'grot spots' also. The link between the sight of plants and stress reduction was also emphasised by the number of comments from both the workshop and the questionnaire that described the natural environment as 'relaxing' therefore the importance of green space especially around treatment areas was emphasised. This study has shown that all users of a hospital were able to identify areas of natural environment and were able to agree on the importance of such.
\end{abstract}

Keywords: Nursing, Environment, Green Initiative, Cancer, Stress

\section{Introduction}

Green infrastructure is a region's life support systemthe network of natural environmental components and green and blue spaces that lies within and between the cities, towns and villages and provides multiple social, economic and environmental benefits (Green Infrastructure North West, 2006).

National surveys in several countries have highlighted the common association with stress reduction and exposure to the natural environment (Grahn and Stigsdotter, 2003; Berg et al., 2010). For people with serious illness access to a green environment provide important benefits of physical, emotional, social and spiritual well-being. Unruh (2010) highlighted a key role of gardening as a coping strategy for living with stressful life experiences. Cimprich and Ronis (2003) suggested that encouraging regular exposure to the natural environment (they suggest up to $120 \mathrm{~min}$ per week) could help to ameliorate intentional fatigue in cancer patients. Tse (2010) also highlighted the positive effects that indoor greenery had upon nursing home residents, noting an increase in social networking which would imply that indoor green space can be as beneficial as outdoor exposure. Furthermore, Kaufman and Lohr (2004) have noted that wide canopy trees initiate a positive emotional response in individuals. There is also evidence to suggest that consistent exposure to high impact natural settings encourages wider existential reflection on the meaning of life with associated goal and 
priority re-evaluation, issues that may be poignant living with a diagnosis of cancer (Mayer et al., 2009).

The importance of a pleasing environment in promoting emotional well-being in healthcare professionals was explored by Rose and Glass (2010). They suggested that access to garden areas was an important self-nurturing strategy. Self-nurturing was seen as crucial in allowing healthcare professionals as providing a method of dealing with the stress of care delivery. This reinforces the stance of Ulrich (2002) who suggested that, not only, did access to the natural environment reduce staff stress and improve job satisfaction, it conceivably contributed to recruitment also-a suggestion first postulated by (Cooper-Marcus and Barnes, 1995).

Thus it can be sen that the consensus of academic and health care opinion is that green space both in and outside of institutions is both beneficial and desirable. However there is little in the literature to suggest that patients and staff recognise or identify 'good' and 'bad' natural environments. This study reports an exploration of the green environment around a large cancer treatment centre in the United Kingdom that was carried out to evaluate the external hospital environment and the perceptions of various users of the hospital sites.

\section{The Study}

Aim

The aim of this study was to investigate whether the individuals who used the hospital (staff, patients and volunteers) and local residents could identify the advantages of a green infrastructure and could comment upon the existing GI examples and also suggest areas that would benefit from a greener environment.

\section{Design}

This was a mixed methods design, primarily quantitative but with a qualitative component. Quantitative data was gathered via a questionnaire whilst the qualitative elements came from a workshop.

\section{Participants}

We recruited 14 individuals who use the hospital, hospital staff, patients, local residents and volunteers (Fig. 1), to take part in an environment mapping exercise and a 'Spaceshaper' workshop. We also developed an open access questionnaire-available to all service users and providers which was completed by 368 individuals (Table 2).

\section{Data Collection}

The Spaceshaper workshop strategy was developed by the Commission for Architecture and the Built Environment in the England to enable the quality of any place to be measured at a particular time. This is done by collecting the views of different site users through a structured site visit, detailed questionnaire and follow up discussion all led by trained Spaceshaper facilitators.

The mapping exercise was undertaken to assess the current Green Infrastructure (GI) provision on the hospital site and to identify any gaps in provision together with scope for improvement. Participants took part in a $30 \mathrm{~min}$ site tour to look at a handful of the key areas on the site. The tour included areas where greenery or some greenery already existed (e.g., the garden, the patient entrance, canteen area) and also to where green provision is currently either very low or nonexistent (such as views from corridor areas).

The subsequent workshop was presented in three key stages:

- In two groups, participants used a map and their own knowledge of the site to discuss and identify areas where they thought existing green provision was satisfactory or working well (hot spots) and also where there are opportunities for improvement either to existing greenery or in those areas that are void of any greenery or in obvious need of improvement (grot spots). This information was captured via a mapping exercise

- The 'functionality' of Green Infrastructure (G.I.) was discussed, i.e., what purpose, role or function does greenery actually 'do'

- The emotional and practical responses to G.I. functions were addressed under the following two question headers. The participant's were asked two questions:

- Why is G.I. Important to me

- Why is G.I. important to the wider community

The issues raised by the workshop participants were congruent with a previously administered questionnaire that had been accessible to the wider worker/user community. The questionnaire collected user information regarding whether the respondent was a patient, a carer accompanying a patient, a visitor, a member of staff, a volunteer, or other.

The questionnaire then asked if the respondent noticed greenery around the hospital, where that greenery was and whether it had a positive impact upon them, their working environment and other people with whom they interacted. We also asked which green space areas the respondent used and whether the respondent thought that more greenery would improve the working environment

This was distributed via the staff intranet, a drop-in event and the insitution Monthly 100 Patient questionnaire. We then collated all of this information and fed this into Survey Monkey to analyse the results. 


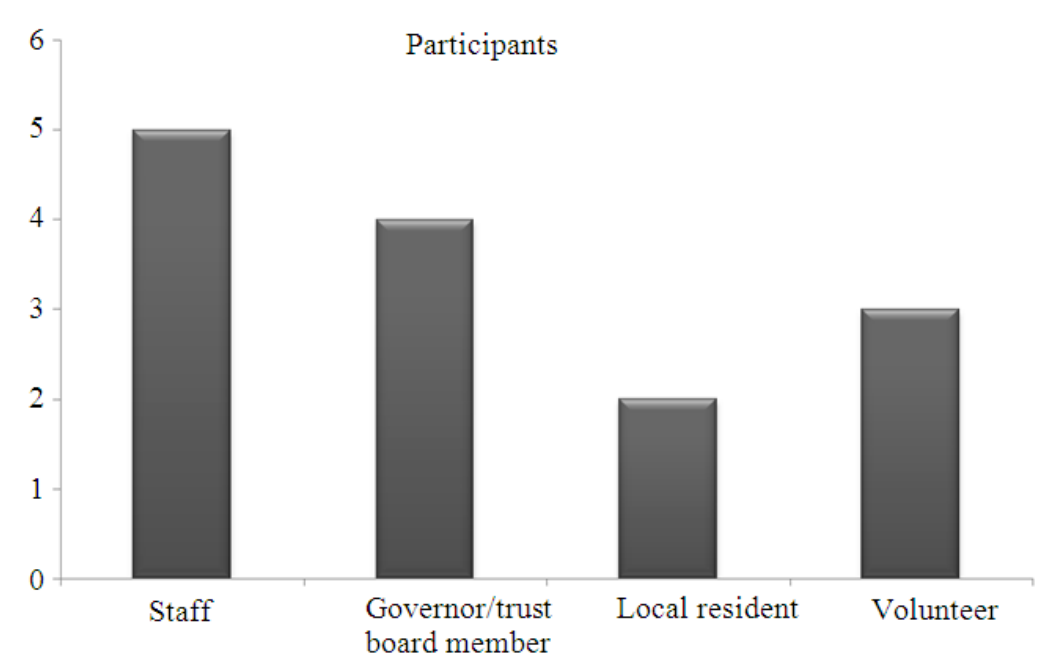

Fig. 1. Workshop participants

\section{Ethical Considerations}

This study was categorised by the participating institution and the National Research Ethics Service as a combination of audit and service development and did not require ethical approval. It was subjected to ethical review by the Faculty Ethic Committee of the academic partners and approval was obtained.

\section{Results}

\section{Questionnaire}

The aim of the questionnaire was:

- To obtain a wider perspectives of the green requirements of the institution

We had 368 responses (Table 2).

The overwhelming numbers of respondents were patients $(61.9 \% \mathrm{n}=227)$, closely followed by staff $(28.6 \% \mathrm{n}=105)$.

Respondents were very aware of the green spaces and the garden environments around the hospital with $85.4 \%$ $(n=311)$ of respondents stating that they had noticed greenery around the hospital. The most obvious green space was the 'glass corridor', which linked the main entrance to the hospital proper. This corridor look out into a landscaped quadrangle which has bushes for wildlife and a fountain, of the 305 people who gave examples of green space, $132(43 \%)$ cited this plot a further 64 people $(20 \%)$ noted the hospital conservatory as a valued green environment.

We asked respondents' if they thought that green space had a positive effect upon the hospital environment. $36.4 \%$ of respondents agreed that it did (n $=134)$. Larger proportions were less sure $(n=231$,
$62.8 \%$ ). However, a larger percentage of hospital users found that greenery had a positive effect upon their own experience of the hospital $(79.3 \% \mathrm{n}=292)$

We also asked people whether being able to see some kind of green environment during their encounter with the hospital was important to them $73.1 \%(n=264)$ strongly agreed that this was the case. We then asked our respondents why that was. Table 3 shows the three most frequent response categories.

So, it can be seen that the existing green spaces around the hospital were recognised by all the users of the hospital site as having a great contribution to the overall well being of the hospital community. Lack of time in accessing green space was highlighted by 6 respondents with comments such as:

- I don't usually have the time to use the green space but enjoy looking at it on my way round the hospital. (2)

And:

I do not have time to use any of the areas (3)

One staff respondent noted the difficulty in actually getting access to the green spaces:

$$
\text { “...the garden benches are usually occupied....." }
$$

As a corollary to that question we invited our respondent to tell us where they would like to see more greenery. About 185 individuals responded, their answers are shown in Fig. 3.

The many entrances into the hospital were identified by 48 respondents $(28.1 \%)$ as the key areas of the site that would benefits from more greenery. These correspond to a number of the 'grotspots' identified in Fig. 2. 


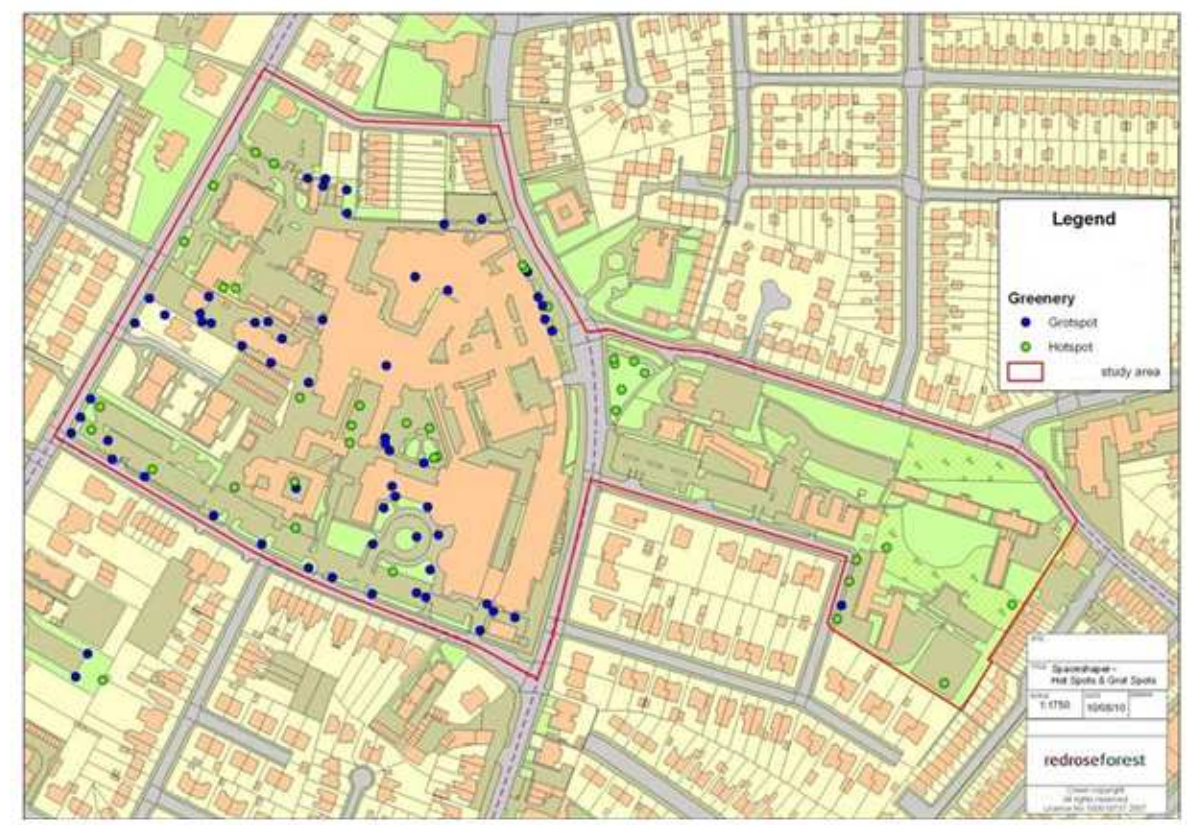

Fig. 2. Hotspots and grot spots

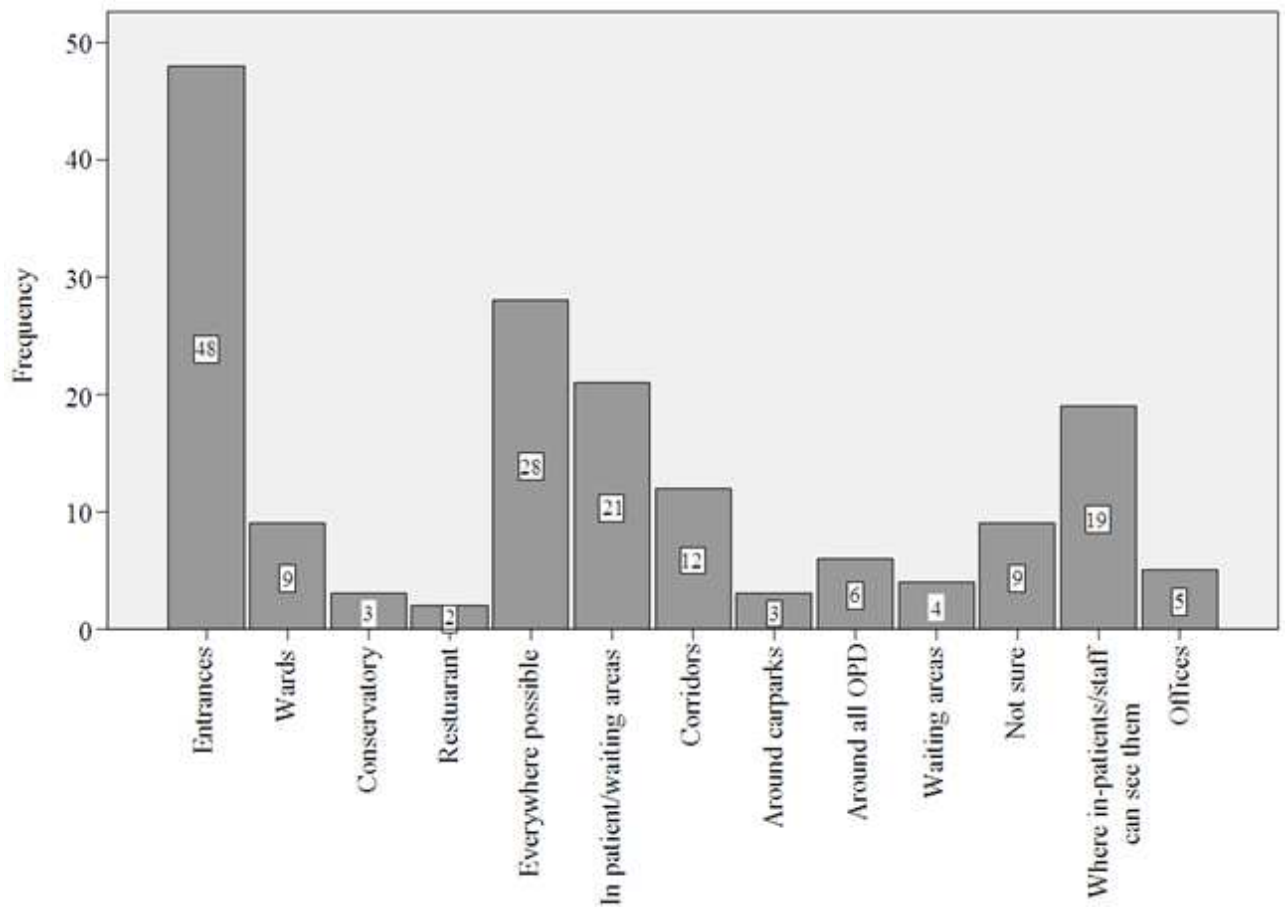

Fig. 3. Where would you like to see greenery

A number of respondents $(n=2816.4 \%)$ indicated that the greener the environment was the more they would like it by suggesting that greenery should be place 'everywhere possible'. The majority of responses focused upon patient areas and did not seem to acknowledge that the staff may find a greener environment beneficial; only 5 respondents (2.9\%) suggested that office space might be enhanced by plants.

Not everyone was enthusiastic about the idea of providing greener around the hospital site; we record 5 negative comments, which focused mainly around concerns of space, for example: 
Table 1. What does GI do for the hospital

\begin{tabular}{|c|c|c|c|}
\hline Escape & Nature & Therapeutics & Aesthetics \\
\hline $\begin{array}{l}\text { Provides a link to } \\
\text { physical and visual } \\
\text { Exterior spaces } \\
\text { Connection to the } \\
\text { outside and the seasons } \\
\text { Can give privacy or somewhere } \\
\text { to go, a quiet space } \\
\text { Provides a place to escape } \\
\text { from the ward/office }\end{array}$ & $\begin{array}{l}\text { Attracts and supports } \\
\text { Wildlife } \\
\text { Natural habitat } \\
\text { Attracts birds and insects }\end{array}$ & $\begin{array}{l}\text { Therapeutic } \\
\text { Relaxation } \\
\text { Helps you breathe } \\
\text { Aids the healing process } \\
\text { Provides distraction } \\
\text { Well maintained = } \\
\text { increased confidence }\end{array}$ & $\begin{array}{l}\text { Sensory stimulation } \\
\text { Aesthetics-softens the } \\
\text { interior and appearance/feel } \\
\text { of the hospital } \\
\text { Sense of joy } \\
\text { Sense of serenity/calm } \\
\text { Softens the environment } \\
\text { Provides colour and } \\
\text { cover/shade }\end{array}$ \\
\hline
\end{tabular}

Table 2. Questionnaire respondents

\begin{tabular}{lcr}
\hline Answer options & Response percent & Response count \\
\hline Patient & 61.9 & 227 \\
Carer & 0.3 & 1 \\
Visitor & 1.9 & 7 \\
Staff & 28.6 & 105 \\
Volunteer & 7.1 & 26 \\
Other & 0.3 & 2 \\
& 368.0 & \\
\hline
\end{tabular}

Table 3. The importance of green space

\begin{tabular}{|c|c|c|}
\hline Key word & Frequency & Sample comments \\
\hline relax(ing) & 38 & $\begin{array}{l}\text { Diversional/lifts spirits/something to focus on (5) } \\
\text { It's an escape (2) } \\
\text { Like being at home (2) } \\
\text { Less clinical (3) } \\
\text { Relaxing (14) } \\
\text { Helps cope with stress (3) }\end{array}$ \\
\hline Calm(ing) & 15 & $\begin{array}{l}\text { Calming and reassuring, makes hospital more attractive (1) } \\
\text { peaceful calming }(6) \\
\text { Encourages a feeling of calm, things growing and beautiful } \\
\text { flowers enhance moods of happiness ( } 3 \text { ) }\end{array}$ \\
\hline Spiritual $/ \operatorname{mood}$ & 11 & $\begin{array}{l}\text { To see things growing lifts the spirits (4) } \\
\text { I work in an office with no window or natural light to go to the } \\
\text { gardens at lunch time lifts your spirits and morale. (1) } \\
\text { Has a very positive effect on your mood and helps everybody to } \\
\text { keep in touch with the seasons and their changes even in difficult times (3) }\end{array}$ \\
\hline
\end{tabular}

"not sure if there is enough space"

And:

$$
\begin{aligned}
& \text { "none-all space needed for medical } \\
& \text { purposes" }
\end{aligned}
$$

The last is interesting since it implies that the respondent did not recognise the health related effect that green space can offer. Another respondent seemed to agree since they suggested that a greener environment was:

$$
\text { "pleasant but not necessary" }
$$

\section{Space Shaper Comments}

Even with only a brief tour of the hospital site participants were clearly able to identify areas of green space that appealed to them. Figure 2 shows the 'Hotspots' and 'Grotspots' mapping exercise. It can be seen that not only were there more Grotspots (60) than Hotspots (30) it is notable that many of the grot spots were centred around hospital entrances or at the rear of hospital buildings. Generally, the more greenery, notably trees rather than just lawns or shrubs that could be seen the less likely the evaluators were to find the area unpleasant. This resonates with the work of Kaufman and Lohr (2004).

The group were asked to list what they thought a green initiative actually did for the hospital environment. Their responses fitted into 4 broad themes (Table 1). All of the responses, except one, suggested that access to green initiatives' were beneficial. Green spaces were seen as place one could escape to by both patients and staff. Equally local residents and patients felt that a green initiative contributed to the aesthetics of the clinical 
environment as it "...softens the appearance and feel of the hospital". It was interesting that someone made the point that if the gardens were well maintained it "...increased confidence" in the hospital. In times of economic austerity the importance of the external image of an institution cannot be underestimated. However, one participant sounded a note of caution, noting that, "Weeds are annoying and irritating so it will need maintaining".

This last point was also picked up by a number of staff members who, when responding to the question "Why is GI important to me?" noted:

"A tidy garden shows that the employer is bothered about workforce pleasure and relaxing. Makes you feel positive on a 'dull or stressful' day."

And:

"An improved environment could help staff
feel valued (more than they already feel!)"

The notion that a garden or natural view could assist with stress reduction was also highlighted by patients, when a green environment was seen as:

"Very important as it has a calming effect and deflects ones mind particularly if going for treatment."

Access to a green environment Ws also seen as an important link to a 'normal life' and the outside world:

When visiting or being treated [at centre], it is good to be reminded that there is a normal world outside the hospital

\section{Discussion}

The work carried out in this study has indicated that patients, staff and other individuals associated with institutional use recognise the provision and lack of green environment. A number of the respondents were patients attending for treatment and could conceivably be expected to be stressed and to have the attentional fatigue described by Cimprich and Ronis (2003), however it is clear that, even sub-consciously, the impact of the environment is recognised by these individuals. The focus of all of the respondents appeared to be upon the benefits to the patients with only a few instances of benefits to staff being cited, volunteers and carers were not specifically mentioned at all. This may not necessarily be surprising given the nature of the institution but may also reflect the attitudes of health care professionals towards carers as outlined by Allen (2000) in which carers are most typically seen as providing "comfort" rather than playing an active role in the care of the patient. Outpatient areas were identified as requiring greenery but, again, the implications were around the needs of the patients rather than the carers.

It was striking that even without being prompted the areas of the hospital that were identified by the questionnaire respondents as being most on need of green planting were the entrances; these were identified as 'grot spots' by the workshop participants also. This would suggest that even familiarity with a site associated with stressful and unpleasant treatments, as one would expect from many of our respondents, does not prevent an awareness of the less satisfactory visual and spiritual elements of the experience. The link between the sight of plants and stress reduction was also emphasised by the number of comments from both the workshop and the questionnaire that described the natural environment as 'relaxing' therefore the importance of green space especially around treatment areas was emphasised. It was noted that staff in the hospital also identified such areas as 'relaxing' but also seemed to imply that they viewed them as the property of patients, noting that there was difficulty in accessing green space because patient used them. It may be fruitful to undertake further research in the field focussing upon the needs of staff for green spaces that are dedicated to them alone, particularly since green spaces were often seen by practitioners as places to escape from the stresses of care delivery and support.

Overall the provision of green spaces was seen as providing beneficial effects to all hospital users although it was not within the remit of this study to attempt to quantity or evaluate what these benefits were. However, the Department of Health in the United Kingdom in 2011 issued guideline to all NHS hospital encouraging them to indentify underused areas of hospital property that could usefully be sold off for housing developments (Flory, 2011), an act that may have the effect of significantly reducing the amount of green space available on hospital sites.

\section{Conclusion}

Whilst the study has limitations, notable the context specific nature of both the investigative site and the respondents; i.e., a single cancer treatment hospital and its workers and users, it does provide preliminary evidence as to the importance of green space in treatment areas and suggests that both service users and service providers can identify 'good' spaces and 'bad' ones. Future studies, which focus upon general hospitals, are recommended in order to strengthen the case for the protection of green space in hospital environs. In addition, studies, which 
explore the stress levels of staff, patients and carers and the effects of green spaces on those stress levels would build upon the work presented in this study.

In conclusion, this study has shown that all users of a hospital were able to identify areas of natural environment and were able to agree on the importance of such. The beneficial actions of green environment where often seen as exclusive acting upon the patients, with the need of the healthcare staff, carers and volunteer staff being acknowledged only marginally. The increased development of green spaces around hospital is seen as important by both service users and providers. This study has shown that all members of the hospital community are able to recognise area for improvement and we would suggest that this level of user involvement is crucial to any proposed green space development.

\section{Funding Information}

The authors have no support or funding to report.

\section{Author's Contributions}

All authors equally contributed in this study.

\section{Ethics}

This article is original and contains unpublished material. The corresponding author confirms that all of the other authors have read and approved the manuscript and no ethical issues involved.

\section{References}

Allen, D., 2000. Negotiating the role of expert carers on an adult hospital ward. Soci. Health Illness, 22: 149-171. DOI: 10.1111/1467-9566.00197

Berg, A.E.V.D., J. Maas, R.A. Verheij and P.P. Groenewegen, 2010. Green space as a buffer between stressful life events and Health. Social Sci. Med., 70: 1203-1210.

DOI: 10.1016/j.socscimed.2010.01.002
Cooper-Marcus, C. and M. Barnes, 1995. Gardens in the Healthcare Facilities: Uses, Therapeutic Benefits and Design Recommendations. Ist Edn., Center for Health Design, California, ISBN-10: 0963893823, pp: 70.

Cimprich, B. and D.L. Ronis, 2003. An environmental intervention to restore attention in women with newly diagnosed breast cancer. Cancer Nur., 26: 284-292. PMID: 12886119

Flory, D., 2011. Memo: Accelerating the release of public sector land for development.

Grahn, P. and U.A. Stigsdotter, 2003. Landscape planning and stress. Urban Forestry Urban Green, 2: 1-18. DOI: 10.1078/1618-8667-00019

Kaufman, A.J. and V.I. Lohr, 2004. Does plant color affect emotional and physiological responses to landscapes. Supported Can. Int. Dev. Agency.

Mayer, F.S., C.M. Frantz, E. Bruehlman-Senecal and K. Dolliver, 2009. Why is nature beneficial. Role Connectedness Nature. Environ. Behav., 41: 607-643. DOI: $10.1177 / 0013916508319745$

Tse, M.M., 2010. Therapeutic effects of an indoor gardening programme for older people living in nursing homes. J. Clinical Nurs., 19: 949-958. DOI: $10.1111 /$ j.1365-2702.2009.02803.x

Rose, J. and N. Glass, 2010. An Australian investigation of emotional work, emotional well-being and professional practice: An emancipatory inquiry. J. Clinical Nurs., 19: 1405-1414. DOI: $10.1111 /$ j.1365-2702.2009.02997.x

Ulrich, R.S., 2002. Health benefits of gardens in hospitals. Proceeding of the Plants People International Exhibition Floriade, (IEF' 02), pp: 1-10.

Unruh, A., 2010. The meaning of gardens and gardening in daily life: A comparison between gardeners with serious health problems and healthy participants. Acta Horticulturae, 639: 67-73. 